Article

\title{
Socio-Economic Potential Impacts Due to Urban Pluvial Floods in Badalona (Spain) in a Context of Climate Change
}

\author{
Eduardo Martínez-Gomariz ${ }^{1,2, *(1)}$, Luca Locatelli ${ }^{3}$, María Guerrero ${ }^{1}$, Beniamino Russo ${ }^{3,4}{ }^{(\mathbb{D}}$ and \\ Montse Martínez ${ }^{3}$ \\ 1 Cetaqua, Water Technology Centre, Environment, Society and Economics Department, \\ 08940 Cornellà de Llobregat, Spain; maria.guerrero@cetaqua.com \\ 2 FLUMEN Research Institute, Universitat Politècnica de Catalunya, 08034 Barcelona, Spain \\ 3 AQUATEC (SUEZ Advanced Solutions), 08038 Barcelona, Spain; luca.locatelli@aquatec.es (L.L.); \\ brusso@aquatec.es (B.R.); mmartinezp@aquatec.es (M.M.) \\ 4 Group of Hydraulic and Environmental Engineering, Technical College of La Almunia (EUPLA), \\ University of Zaragoza, 50100 Zaragoza, Spain \\ * Correspondence: eduardo.martinez@cetaqua.com; Tel.: +34-933-124-899
}

Received: 14 November 2019; Accepted: 13 December 2019; Published: 17 December 2019

\begin{abstract}
Pluvial flooding in Badalona (Spain) occurs during high rainfall intensity events, which in the future could be more frequent according to the latest report from the Intergovernmental Panel on Climate Change (IPCC). In this context, the present study aims at quantifying the potential impacts of climate change for the city of Badalona. A comprehensive pluvial flood multi risk assessment has been carried out for the entire municipality. The assessment has a twofold target: People safety, based on both pedestrians' and vehicles' stability, and impacts on the economic sector in terms of direct damages on properties and vehicles, and indirect damages due to businesses interruption. Risks and damages have also been assessed for the projected future rainfall conditions which enabled the comparison with the current ones, thereby estimating their potential increment. Moreover, the obtained results should be the first step to assess the efficiency of adaptation measures. The novelty of this paper is the integration of a detailed 1D/2D urban drainage model with multiple risk criteria. Although, the proposed methodology was tested for the case study of Badalona (Spain), it can be considered generally applicable to other urban areas affected by pluvial flooding.
\end{abstract}

Keywords: pluvial floods; flood risk assessment; climate change; damages; vehicles; properties; pedestrians

\section{Introduction}

According to the latest report from the IPCC [1], heavy rainfall could be more frequent in many areas of the planet over the next years. The greater uncertainty related to precipitation with respect to other climate variables such as temperature or sea level rise, requires local studies that apply spatial and temporal downscaling techniques in order to obtain conclusive results. An extreme and moderate rainfall increment, in terms of frequency and magnitude, might aggravate the consequences of urban floods thereby causing increasing impacts on people safety and the economy of cities.

Badalona, with more than 215,000 inhabitants within its administrative limits on a land area of more than $21.2 \mathrm{~km}^{2}$, is located in eastern Catalonia (Spain) and is part of the Barcelona Metropolitan Area (in Spanish AMB) (Figure 1). It is situated on the left bank of the Besòs River facing on the Mediterranean Sea, and backed by the Serra de la Marina mountain range. This city is one of the six research sites across Europe (Portugal, Spain, Cyprus, Germany, the Netherlands, and Norway) of the EU project BINGO (Bringing Inovation to Ongoing water management-a better future under 
climate change (2015-2019)). The project strives to provide practical knowledge and tools to end users, water managers, and decision and policymakers for a better informed decision making process under the uncertainties of climate change. The city administrative division consist in six districts and 24 subdistricts, and the average population density of the city is approximately $10,000 \mathrm{inhab} / \mathrm{Km}^{2}$, although this figure can increase significantly in some districts of the old town and the city centre. The morphology of Badalona presents areas with high gradients (close to Serra de la Marina) and flat areas near the Mediterranean Sea. Moreover, the land was strongly urbanized during the last decades. These characteristics, together with the Mediterranean rainfalls characterized by high intensity and short duration, leave the city in a flood-prone situation. All these aspects put urban drainage in Badalona in the spotlight as urban flash floods happen in several critical areas with significant economic damages and high hazard conditions for pedestrian and vehicular circulation. Its drainage network is mainly a combined sewer system with $318 \mathrm{~km}$ of conduits, $26 \%$ of them allowing man-entry. There are nine catchments in the city, most of which discharge from the mountain to the sea. Waste water is intercepted by a main sewer placed along the coastal area that conveys it to the Besòs Waste Water Treatment Plant (WWTP) (Figure 1b).

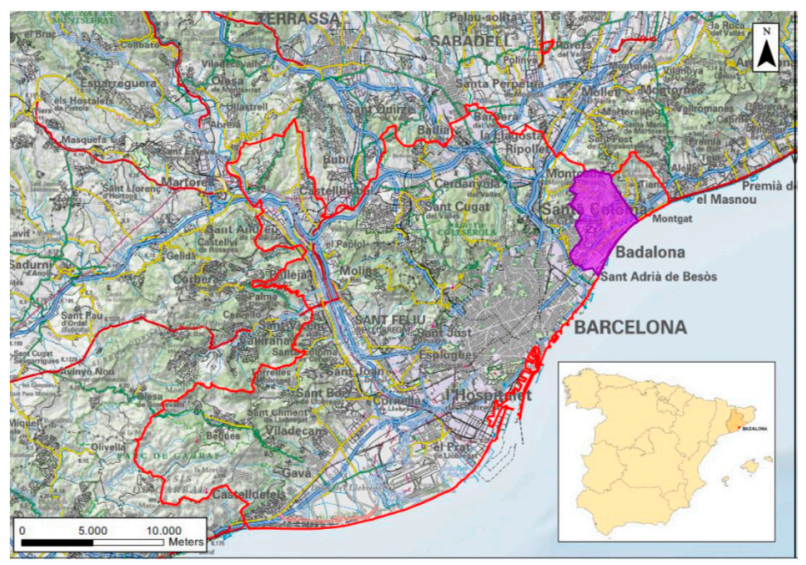

(a)

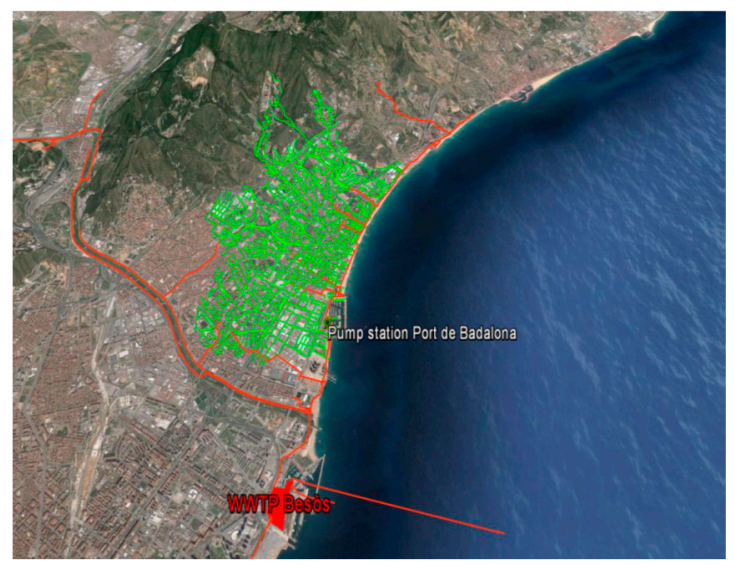

(b)

Figure 1. (a) Badalona location and Barcelona Metropolitan Area (in Spanish AMB) administrative limits (in red), and (b) Badalona drainage network. The background maps were provided by the Cartographic and Geological Institute of Catalonia (ICGC).

Therefore, according to the frequent pluvial floods in Badalona that cause sewer surcharging the need of a risk assessment arises, specially taking into account the regulations that have been established with the European Flood Directive [2]. Although in Spain all efforts to accomplish the flood risk management plans required by the European Flood Directive [2], it has to be stressed the importance of managing appropriately the ever more frequent pluvial urban floods [3].

In this research, according to a similar risk concept proposed by Turner et al. [4], a comprehensive flood risk assessment has been conducted, considering social (intangible) and economic (direct and indirect tangible) losses. The pluvial flood risk assessment carried out within CORFU project (http://www.corfu7.eu/) for the Spanish case study in the Raval District [5] has been considered as the baseline, although novel methodologies and updated criteria have been implemented.

Residents in urban areas, such as Badalona, conduct a wide variety of activities, some of which involve vehicles, during the day under different weather conditions, which makes people safety an important issue. A vehicle exposed to flooding may become buoyant and be washed away with potential injuries and fatalities. Such vehicles cause additional disruptions to traffic that is already affected by flooding, which may lead to substantial indirect economic impact, especially in urban areas. For these reasons, the main objective of the flood social risk assessment is the people's safety, focused on their stability when exposed to water flows [6] and their potential injuries due to the loss of 
stability of vehicles, either because there are passengers inside or pedestrians may be impacted by these massive debris.

On the other hand, in terms of economic damages, over the period 1996-2016 more than 60 flood events caused damages to properties in Badalona, summing up more than 1.8 Million Euro in 499 claims according to the data received from the Spanish insurance company Consorcio de Compensación de Seguros (CCS). The CCS is a state-owned enterprise attached to the Ministry of Economy and Enterprise that performs several functions complementing the Spanish Insurance Industry, enhancing its stability and protecting the insured. Regarding damages to vehicles, more than 160 claims have been reported in the same period (1996-2016) with a total economic damage of 478,000€ (Figure 2).

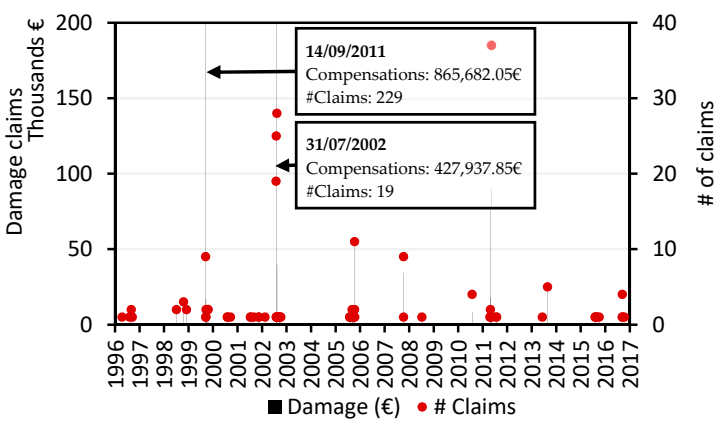

(a)

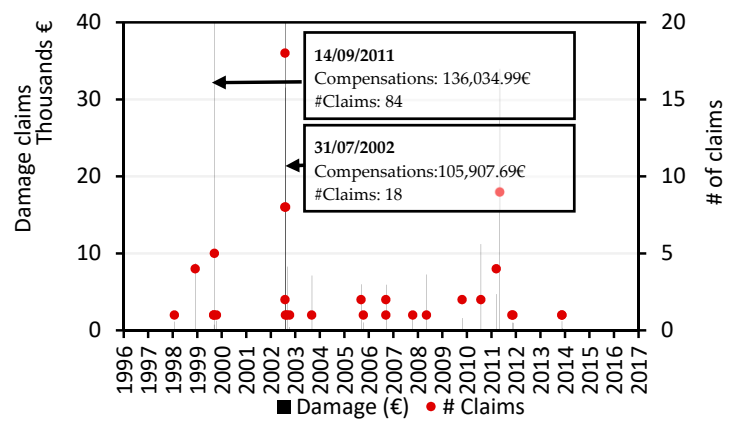

(b)

Figure 2. Claims and compensations regarding (a) properties and (b) vehicles in Badalona due to floods occurred since 1996.

The potential for cities to be damaged is notably high due to the high spatial density of people and values [7]. Studies to estimate flood damages are mainly focused on properties, using depth damages curves $[7,8]$. Depth damage curves can measure damage percentages or may be represented based on monetary units over surface unit, format more useful for mapping purposes. Several proposals of flood damage curves can be found worldwide, for example in:

- Australia with the Queensland Government guidelines [9].

- USA with the guidelines proposed by the U.S. Federal Emergency Management Agency [10].

- $\quad$ Spain (Valencia) with the criterion proposed within the EU Project CRUE [11].

- Italy with a particular development proposed by the Research Institute for Geo-hydrological Protection of Turin (Italy) for river Boesio flooding [12].

- United Kingdom with the criterion proposed in the Multicoloured Manual [13].

- Spain (Barcelona) in the framework of the EU Project CORFU [14] new damage curves focused on urban pluvial flooding were performed for the district of El Raval (Barelona).

In urban flood risk studies, direct and tangible damage assessments are common, which are related to the immediate physical contact of flood water and easily specified in monetary terms [15]. Direct and tangible damages to properties vary according to the type of property, its value, and the restitution costs to initial state [16]. Flood direct damages estimation for properties can be conducted within an urban area making the geo-referenced type of buildings and the corresponding damage curves available, and with the help of GIS tools. In addition, vehicles are susceptible of being damaged by floods, which in case of losing their stability they may collide with other urban elements or even cause injuries to residents. Therefore, the estimation of tangible and direct damages should be considered in a comprehensive damage assessment. Although, this assessment has been conducted to a lesser extend within the literature consulted, the studies found present a similar assessment that for properties by considering damage curves for vehicles. Some studies related flood damage assessment for vehicles are presented in Martínez-Gomariz et al. [17]. 
Furthermore, flooding also induces indirect damages that may occur-in space or time-outside the actual event [18]. The focus of this concern is on economic losses from the cascading effect of floods and business interruption that relate specifically to flooded business, which are defined as primary indirect losses [19]. The input-output method is commonly used to estimate short-term impacts [20], because it is relatively simple compared to general equilibrium models.

This paper presents a comprehensive pluvial flood risk assessment for the city of Badalona, in which a diversity of impacts has been considered. Damages assessed include intangible, by analyzing the risks for pedestrians in terms of both their own and vehicles' stability; tangible-direct damages for properties and vehicles, by proposing novel methodologies and criteria to estimate their economic damages; and tangible-indirect damages by implementing existing procedures to estimate the potential economic losses caused by the businesses interruption. Therefore, an elaborated social and economic impacts assessment has been carried out for current and future rainfall conditions, by employing as a basis a detailed 1D/2D hydrodynamic model, covering the entire drainage network of Badalona. This model is characterized in Section 2.1 followed by the description, in Section 2.2, of the rainfall conditions considered for the present and future. The methodology employed to assess the intangible (social) and tangible (economic) flood risks is presented in Section 2.3. Firstly, these risks have been assessed for the current scenario (baseline) and secondly for the future rainfall conditions (business as usual, BAU). Finally, results and conclusions regarding the risks assessment carried out for the current situation and the potential risk increase according to the expected future rainfall conditions are presented in Sections 3 and 4 respectively.

\section{Materials and Methods}

\subsection{Hydrodynamic $1 D / 2 D$ Coupled Model}

A coupled 1D/2D hydrodynamic model was developed, calibrated and validated using InfoWorks ICM (www.innovyze.com). The model covers the whole municipality of Badalona with an extension of $21.7 \mathrm{~km}^{2}$. While the 1D model reproduces the rainfall runoff processes of buildings that drain directly into the 1D drainage network, the 2D model reproduces stormwater runoff of streets, parks, and all areas that are at the terrain level and can be flooded. The 1D and the 2D model continuously interact at all 1D model nodes that are defined as "Gullies 2D". At this nodes the exchange of water is computed using experimental functions [21,22] developed at the Technical University of Catalonia (UPC) that calculate the water flow from the $2 \mathrm{D}$ to the $1 \mathrm{D}$ model and vice versa as a function of the local water level. Flow transferring took into account also inlet clogging factors estimated on the basis of field investigations [23,24]. For every node, a GIS analysis allowed to select the most appropriate UPC function based on street slope, width and type of gullies and also the number of existing gullies were associated to the closest model node. Peculiarity of the model is that part of the rainfall is directly applied to the 2D surface water model and part to the remaining 1D model. Conventional urban drainage modelling applies the rainfall directly to the 1D model [25] and then only manhole surcharge can create flooding. In Badalona, it is believed that part of urban floods come directly from areas (like streets) that have surface drainage systems with poor capacity due a lack of gullies.

The 1D model was developed in 2012 for the Drainage Management Plan (DMP) of Badalona. Within BINGO project, the model was then imported into ICM and updated to include the latest pipes and one detention tank of approximately $30,000 \mathrm{~m}^{3}$. Overall, the 1D model includes approximately $368 \mathrm{~km}$ of pipes, 11,338 manholes, 11,954 sub-catchments, 62 weirs, 4 sluice gates, and 1 detention tank. The full 1D Saint-Venant equation is used to solve the sewer flow. Rainfall-runoff processes were simulated with the SWMM model (included in InfoWorks) that routes flow using a single non-linear reservoir with a routing coefficient that is a function of surface roughness, surface area, and terrain slope and catchment width. Initial losses are generally small for both impervious urban areas and green areas $(\leq 1 \mathrm{~mm})$ and continuous losses for green areas are simulated using the Horton model. The extension of Badalona municipality was divided into 11,954 sub-catchments that were obtained by GIS 
analysis of the digital terrain model $(2 \mathrm{~m} \times 2 \mathrm{~m}$ resolution) and have areas in the range of $0.01-1$ hectares in the urban areas and 1-100 hectares in the upstream rural areas. Each sub-catchment includes GIS derived information of impervious and pervious areas that are used to apply either the impervious or the pervious rainfall-runoff model. Impervious areas were not provided with continuous hydrological losses. The 2D model is based on a unstructured mesh with 199,338 cells that was created on the basis of a detailed digital terrain model (DTM) with a $2 \mathrm{~m}^{2}$ resolution obtained by a LIDAR provided by the Cartographic and geological Institute of Catalonia (precision of $20 \mathrm{~cm}$ in terms of ground elevation). The size of the cells is in the range of $16-64 \mathrm{~m}^{2}$ in the urban area and 70-400 $\mathrm{m}^{2}$ in the upstream rural areas.

The 1D/2D model was quantitatively and qualitatively calibrated and validated by using data from 3 rainfall gauges, 14 water level sensors and flood event videos and photos. Key model performance parameters like root mean squared error, time to peak error, and absolute maximum error were computed and reported in deliverable 3.3 of BINGO project [26], where further details are provided regarding the model and its validation and calibration process.

\subsection{Current and Future Rainfall Conditions Scenarios}

Rainfall intensity-duration-frequency (IDF) curves, performed based on historic recorded time series data in the Fabra Observatory of Barcelona, are employed for urban hydrology studies not just in Barcelona but also across the surrounding municipalities. Therefore, these IDF curves were employed to develop the design storms, based on current rainfall conditions, as inputs for the 1D/2D coupled hydrodynamic model. Due to the proximity of Badalona to Barcelona, the IDF curves are expected to be similar in terms of both intensity and shape. Regarding future rainfall conditions, short term predictions (2015-2024) and long-term projections (2051-2100) were considered. As the short-term rainfall predictions did not indicate changes in terms of intensities, long-term projections were obtained from the project CORDEX. The EURO-CORDEX domain is a standard reference domain for Europe defined as part of the CORDEX Experiment (http://www.cordex.org/). A GCM MPI-ESM routine was employed and verified through the re-analysis of ERA-Interim. The downscaling process was carried out by employing the Regional Climate Model (RCM) COSMO-CLM.

A comparison between historic (1979-2005) and projection (2051-2100) daily rainfall data has been carried out in order to analyse variations (i.e., either increase or decrease) in extreme values from past and future rainfall intensities for different return periods. An extreme values analysis has been conducted by considering a Gumbel distribution for both samples, historic and projections, which were formed by the maximum values of $24 \mathrm{~h}$ rainfall data per year. As Houston et al. [27] state "given that a wet 24-h period will also contain pulses of heavier rainfall of shorter duration, it seems likely that projected uplifts in rainfall over a 24-h period will be associated with an uplift in the severity of sub-daily duration rainfall". Therefore, these intensity values have been compared from historic to future extreme values and for each considered CORDEX scenario (RCP 8.5 and 4.5). An overall increase in $24 \mathrm{~h}$ average intensities for RCP 8.5 was found, and a clear overall average-intensities decrease for almost all return period was observed for RCP 4.5 scenario. Hence, scenario RCP 8.5 was selected to perform the design storms for the risks assessment, as it presented the least favourable results in terms of extreme events.

The historic-future variation percentages, based on $24 \mathrm{~h}$ time resolution, were applied directly on the historic-real Barcelona IDF curves, based on sub-daily durations, in order to obtain the future ones and, so that future design storms can be performed based on the new IDF curves. These variations are called climate change factors and are defined as the ration between the rainfall intensity with a return period $\mathrm{T}$ and a duration $\mathrm{d}$ for a future climate scenario and the corresponding rainfall intensity in the present climate $[28,29]$. Thus, CORDEX results (i.e., RCP 8.4 scenario) have been employed for setting Badalona future scenario and design storms according to the climate change factors obtained (Table 1). It should be noted that there is not a linear relation between the considered scenario emissions and the amount of rainfall that will be obtained. That is to say, not necessarily a more restrictive RCP in terms 
of $\mathrm{CO}_{2}$ emissions will offer higher rainfall increments. This fact was observed here for RCP 4.5, which offered an overall rainfall decrease unlike the RCP 8.5 scenario.

Table 1. Climate change factors according to RCP 8.5 scenario and related to different return periods.

\begin{tabular}{ccccc}
\hline Scenario/Return Period & T02 & T10 & T100 & T500 \\
\hline RCP 8.5 & $15 \%$ & $7 \%$ & $2 \%$ & $1 \%$ \\
\hline
\end{tabular}

\subsection{Full Detailed Flood Risk Assessment in Urban Areas: Badalona}

As introduced previously, flood damages can be classified into direct and indirect damage. The firsts occur due to the physical contact of the flood water with people, property or any other element, while the indirect damages are induced by the direct impacts and may even occur outside the flood event. Moreover, these are further classified into tangible and intangible damage, depending on whether or not these losses can be assessed in monetary values [30]. Table 2 presents a sample of flood damages classified according to the groups that were mention previously. Those considered in the present study are highlighted in bold type.

Table 2. Classification of flood damages (adapted from Velasco et al. [14]).

\begin{tabular}{|c|c|c|c|}
\hline & & \multicolumn{2}{|c|}{ Measurement } \\
\hline & & Tangible & Intangible \\
\hline \multirow[t]{2}{*}{ Form of damage } & Direct & $\begin{array}{c}\text { Physical damage to assets: } \\
\text { Infrastructure } \\
\text { Contents } \\
\text { Buildings } \\
\text { Evacuation and rescue } \\
\text { operations } \\
\text { Agricultural land } \\
\text { Clean-up costs }\end{array}$ & $\begin{array}{l}\text { Fatalities and injuries } \\
\text { Diseases } \\
\text { Historical and cultural losses } \\
\text { Loss of ecological and } \\
\text { environmental goods } \\
\text { Inconvenience }\end{array}$ \\
\hline & Indirect & $\begin{array}{c}\text { Loss of industrial production } \\
\text { Traffic disruption } \\
\text { Emergency costs } \\
\text { Temporary housing of evacuees } \\
\text { Business interruption }\end{array}$ & $\begin{array}{c}\text { Societal disruption } \\
\text { Increased vulnerability of survivors } \\
\text { Undermined trust in } \\
\text { public authorities } \\
\text { Psychological trauma }\end{array}$ \\
\hline
\end{tabular}

A considerable part of the literature on flood damages concerns direct tangible damage [31] while other damage types have received much less attention. However, the present study covers a greater variety of types of damages in a novel and complete social and economic pluvial flood risks assessment. Future Master Drainage Plans, in order to analyse the consequences of climate change, should consider a complete flood risk assessment like the one presented herein. It is expected that the level of security currently adopted by designers of drainage networks will be exceed more frequently, and therefore the impacts caused by floods on streets must be analysed (i.e., dual drainage concept [32]) in order to ensure a safety urban environment for pedestrians and properties.

\subsubsection{Pluvial Flood Social Risk Assessment}

Within the field of urban drainage and storm water management a consensus has been reached regarding the two essential hydraulic parameters (i.e., water depth and velocity) that have to be taken into account when assessing flood hazard for pedestrians. In the studies of Russo et al. $[33,34]$ and of Martínez-Gomariz et al. [35,36], the most common flows during urban storm events, with low flow depth and high velocities, were reproduced in the laboratory through a physical model in real scale.

A sample of 26 subjects was tested in the last experimental campaign carried out by Martínez-Gomariz et al. [35,36] considering different conditions and exposure combinations (i.e., types of shoes, hands busy or free, and visibility conditions). The function $(\mathrm{v} \cdot \mathrm{y})=0.22 \mathrm{~m}^{2} \cdot \mathrm{s}^{-1}$ was proposed as the threshold for the stability of a pedestrians exposed to a water flow produced by a pluvial flood, 
usually characterized by low water depths and high velocities. Based on Martínez-Gomariz et al. [35,36] results, the proposed limits for hazard delimitation in the present study are: Low hazard below the product $(\mathrm{v} \cdot \mathrm{y})=0.16 \mathrm{~m}^{2} \cdot \mathrm{s}^{-1}$, medium hazard for values $(\mathrm{v} \cdot \mathrm{y})$ comprised between $0.16 \mathrm{~m}^{2} \cdot \mathrm{s}^{-1}$ and $0.22 \mathrm{~m}^{2} \cdot \mathrm{s}^{-1}$, and high hazard for those above $(\mathrm{v} \cdot \mathrm{y})=0.22 \mathrm{~m}^{2} \cdot \mathrm{s}^{-1}$. Furthermore, it has been considered that when the water depth exceeds $0.15 \mathrm{~m}$, the hazard is high, irrespective of the product of velocity and water depth. Therefore, low and medium hazard hydraulic conditions are both found below a water depth of $0.15 \mathrm{~m}$. The maximum velocity that assures stability conditions for pedestrians, regardless the water depth, was established as $1.88 \mathrm{~m} \cdot \mathrm{s}^{-1}$. The hazard criterion for pedestrians is represented graphically in Figure 3a.

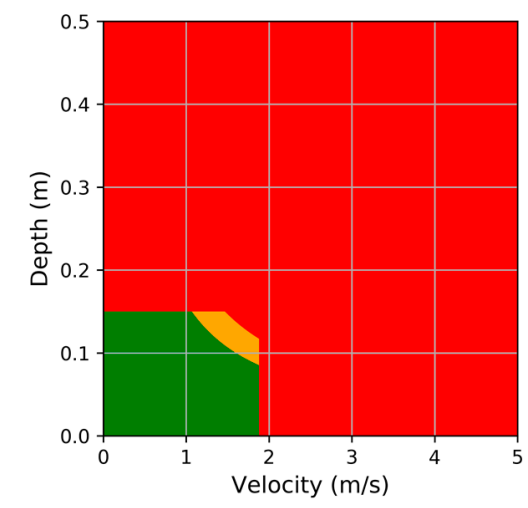

(a)

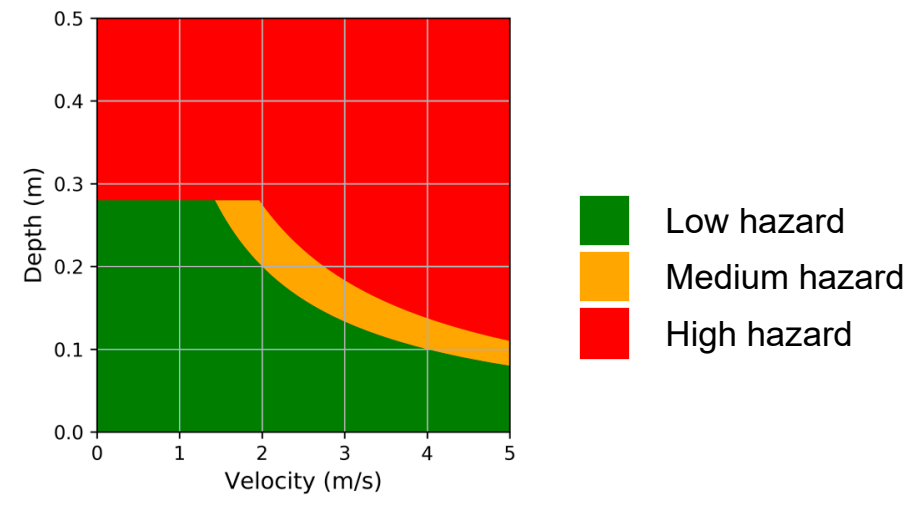

(b)

Figure 3. Hazard criteria for (a) pedestrians; and (b) vehicles.

On the other hand, the studies of Martínez-Gomariz et al. [35,37,38] present a methodology to determine the stability threshold for a vehicle, resulting from several experiments conducted to a wide variety of scaled vehicles. This methodology, which has been adopted here, enables to define a stable area in the domain flow depth-velocity for any real vehicle. According to the article published in La Vanguardia (Spanish newspaper) on the 3rd of September 2015, the three best-selling vehicles in Spain are Citroen C4, Seat Leon and Seat Ibiza. The proposed vehicle for Badalona has been the Seat Ibiza model due its lowest stability according to the methodology proposed by Martínez-Gomariz et al. [35,37], which was calculated considering a friction coefficient between tyres and road of 0.25 . The Seat Ibiza model stability threshold is $(\mathrm{v} \cdot \mathrm{y})_{\text {lower }}=0.40 \mathrm{~m}^{2} \cdot \mathrm{s}^{-1}$ and presents a buoyancy depth of $28 \mathrm{~cm}$. In order to define the hazard limits, a new $(\mathrm{v} \cdot \mathrm{y})_{\mathrm{upper}}$ value is proposed based on the maximum friction coefficient $(\mu=0.75)$ proposed by Gerard [39], which yields an stability threshold of $(\mathrm{v} \cdot \mathrm{y})_{\text {upper }}=0.55 \mathrm{~m}^{2} \cdot \mathrm{s}^{-1}$. Thus, the proposed limits for hazard delimitation are: Low hazard below the product $(\mathrm{v} \cdot \mathrm{y})=0.40 \mathrm{~m}^{2} \cdot \mathrm{s}^{-1}$, medium hazard for the values $(\mathrm{v} \cdot \mathrm{y})$ compressed between $0.40 \mathrm{~m}^{2} \cdot \mathrm{s}^{-1}$ and $0.55 \mathrm{~m}^{2} \cdot \mathrm{s}^{-1}$, and high hazard beyond $(\mathrm{v} \cdot \mathrm{y})=0.55 \mathrm{~m}^{2} \cdot \mathrm{s}^{-1}$ (Figure $3 \mathrm{~b}$ ).

In order to assess the residents' vulnerability in Badalona, a conceptual definition that considers vulnerability as the combination of exposure and susceptibilities has been adopted. The Spanish National Institute of Statistics (Instituto Nacional de Estadística, INE), provided the statistical data of current population per census districts to be employed in the assessment. By setting thresholds of the proposed statistical variables related to the citizens (i.e., indicators) for each census district, these districts can be classified according to their level of vulnerability. Two thresholds were proposed for each indicator considered, and a vulnerability score (i.e., 1 (low), 2 (medium), and 3 (high)) was granted depending on the value of the census district's indicator with respect the proposed thresholds. The indicators considered in order to define the vulnerability of each census district are: General population density, number of vulnerable infrastructure, percentage of people with critical age, and percentage of foreign people. These indicators may affect either the exposure or susceptibilities, and therefore vulnerability. 
The exposure's indicators have been established as the general population density and the units of vulnerable infrastructures. The thresholds for the general population density were set using the medium density of the studied area of Badalona $\left(10,951 \mathrm{inh} / \mathrm{km}^{2}\right)$ and the definition of the National Institute of Statistics of urban area defined as a group of minimum 10 houses in a distance less than $200 \mathrm{~m}$ (equivalent to $384.62 \mathrm{inh} / \mathrm{km}^{2}$ in Badalona). A vulnerable infrastructure in this context is understood as a building or a specific place within the Badalona boundaries, where either a massive concentration of people can potentially occur or specific vulnerable groups of people are expected to be in the building or in their immediate vicinity. In case no vulnerable infrastructure was located within the analyzed census district, the lowest vulnerability score was given to this district (Table 3). When more than one vulnerable infrastructure is located within the district, the highest vulnerability score will be considered. If only one vulnerable infrastructure is found within the district boundaries a medium score was used for the district assessment. Two more indicators are proposed within the susceptibilities consequences' factor, namely percentage of citizens with critical age and percentage of foreign people. By defining critical age as less than 15 years old (i.e., the youngest) and over 65 (i.e., the elders), thresholds have been established as lower than $10 \%$ of the population with critical age for a low vulnerability score and higher than $33 \%$ for a high score. Other values were considered with medium score. Foreign people are not expected to know those specific most hazardous spots, which are well known by the locals. When the foreign percentage within the district is lower than $10 \%$ it will be scored with the lowest vulnerability value, and in case the percentage exceeds the $25 \%$ of the district's population it will be scored with the highest value. The previously-described indicators and thresholds are summarized in Table 3. The final vulnerability level was defined as the average score between the four indicators explained previously, which have been weighted equally. In case the average score is lower or equal than 1.5 a low vulnerability level will be established for the census district, a high level if the averaged score is higher than 2, and medium level for the rest (Table 3).

Table 3. Vulnerability criteria for pedestrians and vehicles.

\begin{tabular}{|c|c|c|c|c|}
\hline \multirow{3}{*}{$\begin{array}{l}\text { Vulnerability } \\
\text { Index/Score }\end{array}$} & \multicolumn{4}{|c|}{ Vulnerability for Pedestrians } \\
\hline & \multicolumn{2}{|c|}{ Exposure } & \multicolumn{2}{|c|}{ Susceptibilities } \\
\hline & $\begin{array}{c}\text { A } \\
\text { General Population } \\
\text { Density (Person/km²) }\end{array}$ & $\begin{array}{c}\text { B } \\
\text { Units of } \\
\text { Vulnerable } \\
\text { Infrastructures }\end{array}$ & $\begin{array}{c}\text { C } \\
\% \text { of People with } \\
\text { Critical Age }\end{array}$ & $\begin{array}{c}\text { D } \\
\% \text { of Foreign } \\
\text { People }\end{array}$ \\
\hline 1 (low) & $\leq 384.62$ & $<1$ & $\leq 25 \%$ & $\leq 10 \%$ \\
\hline 2 (medium) & $384.62<X \leq 10,951$ & $1 \leq X<2$ & $25 \%<X \leq 33 \%$ & $10 \%<X \leq 25 \%$ \\
\hline 3 (high) & $>10,951$ & $\geq 2$ & $>33 \%$ & $>25 \%$ \\
\hline \multirow{3}{*}{$\begin{array}{l}\text { Vulnerability } \\
\text { index/score }\end{array}$} & \multicolumn{4}{|c|}{ Vulnerability for vehicles } \\
\hline & \multicolumn{2}{|c|}{ Exposure } & \multicolumn{2}{|c|}{ Susceptibilities } \\
\hline & \multicolumn{2}{|c|}{$\begin{array}{l}\text { Vehicular flow intensity (VFI) } \\
\text { (veh/day) }\end{array}$} & \multicolumn{2}{|c|}{-} \\
\hline 1 (low) & \multicolumn{2}{|c|}{$<100$} & \multicolumn{2}{|c|}{-} \\
\hline 2 (medium) & \multicolumn{2}{|c|}{$100 \leq X \leq 1000$} & \multicolumn{2}{|c|}{-} \\
\hline 3 (high) & \multicolumn{2}{|c|}{$>1000$} & \multicolumn{2}{|c|}{-} \\
\hline
\end{tabular}

On the other hand, in order to assess the vehicles vulnerability, three levels are proposed based on only one vulnerability indicator: The vehicular flow intensity of the different areas with road traffic. The more traffic flows the more vulnerable is a specific road. This indicator has been related to the exposure which is the only vulnerability's factor taken into account in this case. Table 3 indicates the three vulnerability levels and the thresholds considered for the vehicular flow intensity. The vulnerability maps developed for pedestrians and vehicles are presented in Figure 4. 


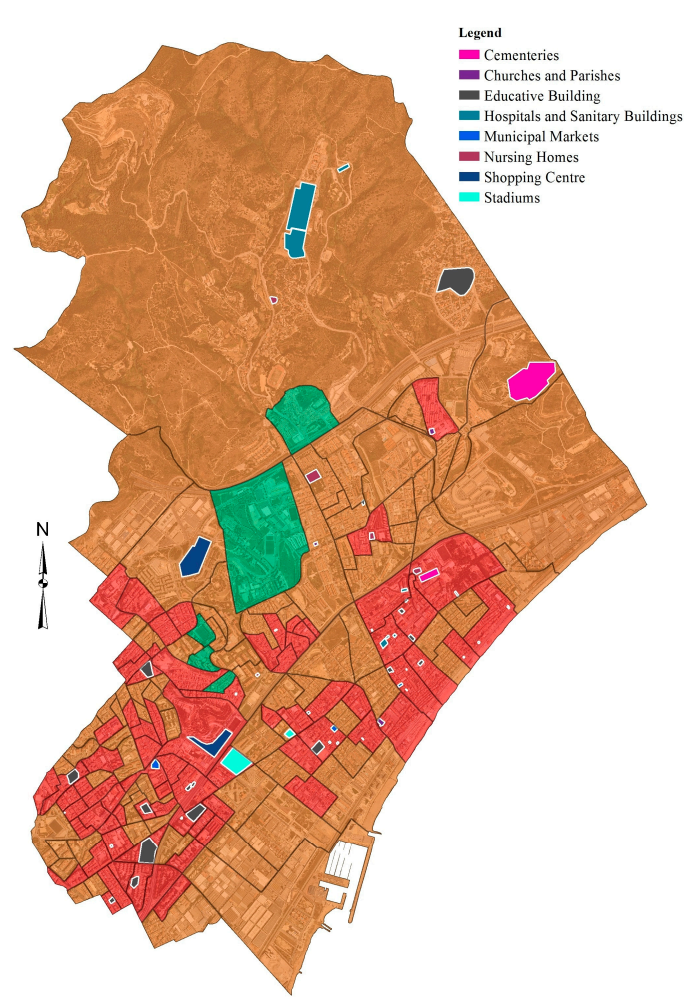

(a)

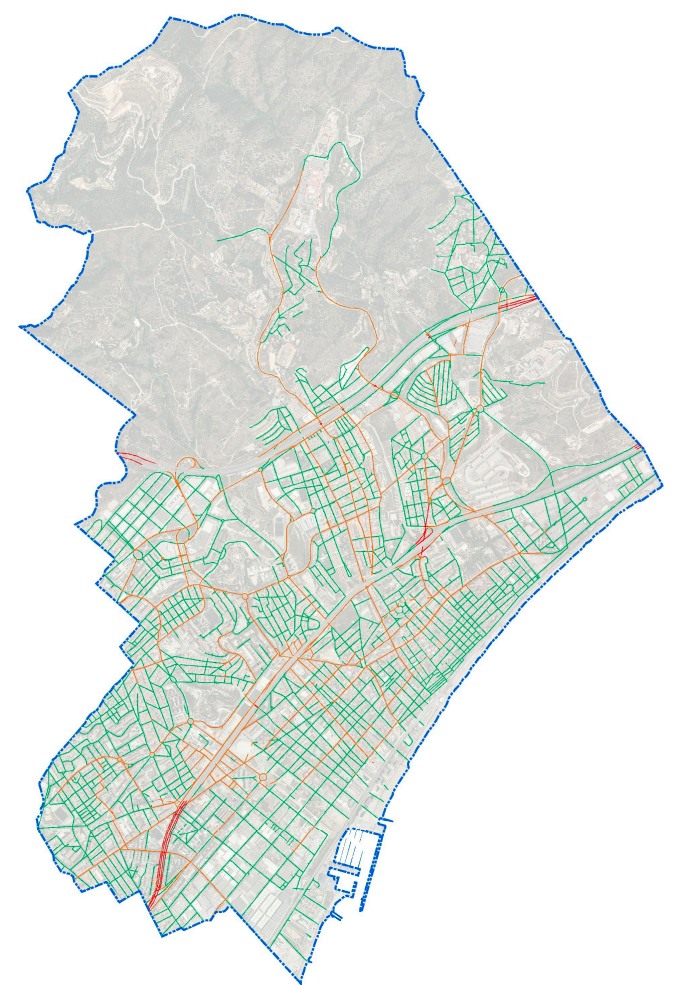

(b)

Figure 4. Vulnerability map for Badalona municipality: (a) Pedestrians, and (b) vehicles.

The selection of these indicators has been agreed with the Badalona city council technicians, who know the most regarding the vulnerabilities of the municipality. However, the indicators selected for other cities could be different because of either their specific needs or unavailability of data. Moreover, due to the data availability, limits of census districts have been the minimum area to establish a vulnerability level in this study, however it could be different in other countries.

The methodologies described previously have been applied to assess risk for pedestrians and vehicles under current and future rainfall conditions (RCP 8.5). In order to determine the risk of a specific area, hazard and vulnerability levels have been overlapped thereby establishing the risk level based on the combinations indicated in the risk matrix of Figure 5. As an example, Figure 6 illustrates the risk maps for both pedestrians and vehicles for a flood produced by a 10-year-return-period design rainfall.

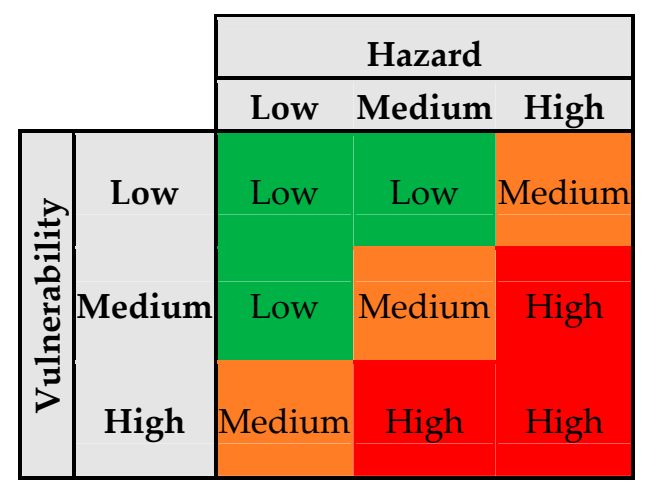

Figure 5. Risk matrix for pedestrians and vehicles. 


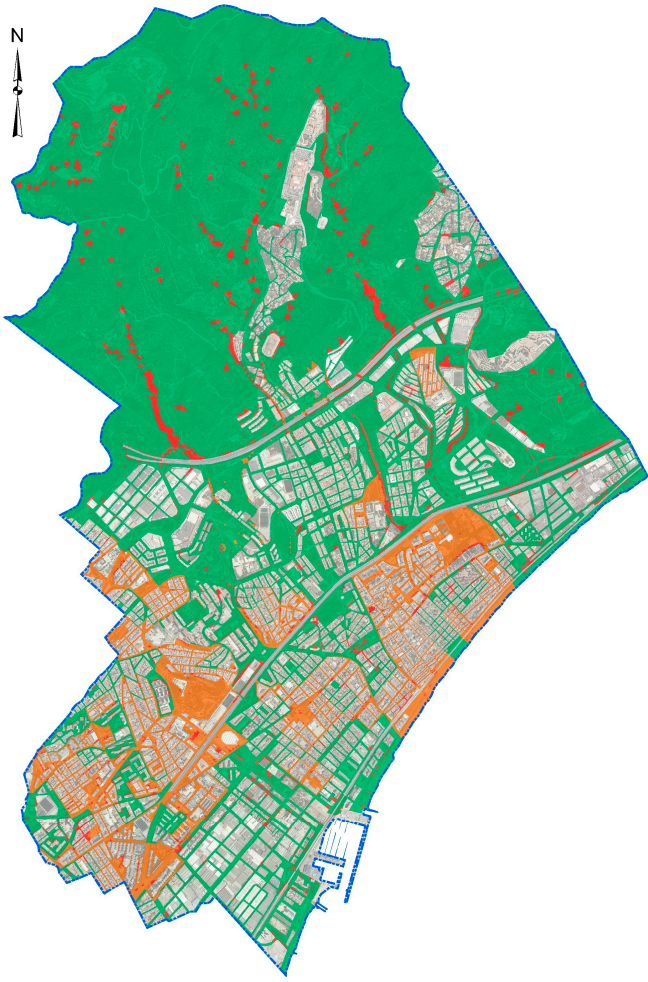

(a)

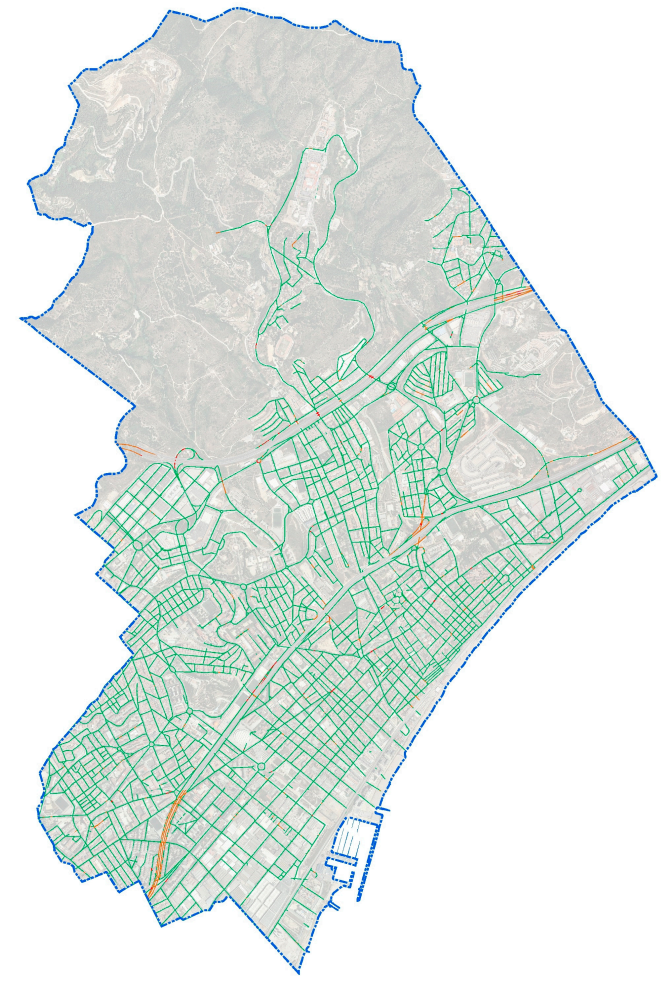

(b)

Figure 6. Risk map for a 10-year-return-period design rainfall regarding (a) pedestrians; and (b) vehicles. Current rainfall conditions.

\subsubsection{Pluvial Flood Economic Risk Assessment}

For the assessment of the direct damages to properties three different types of data were required: Flood maps (hazard), types of properties across the municipality (detailed land uses) and depth damage curves (vulnerability). Flood maps gather the information about hydraulic variables, namely water depths. Land use information capture the type, geometry and use of the properties in the study case area. Depth damage curves are functions that relate the type of building and its characteristics with the water depth to monetary quantify the damages produced by each flood event. Tailored depth damage curves for Badalona have been developed based on an analysis of previous flood claims in Badalona, Barcelona and some other Spanish cities. This work has been carried out with the collaboration of a flood damage surveyor [40]. Fourteen different types of properties have been taken into account to perform their corresponding damage functions as Figure 7a illustrates.

Firstly, flood maps for different design rainfalls related to 2, 10, 100, and 500 years return periods were obtained using the 1D-2D model in order to assess the water depth per each building. Secondly, the land use information was obtained by downloading a shapefile from the Web Portal of the General Directorate of the Spanish Cadastre. This georeferenced database file stores parcels information for the entire municipality, and it is freely downloadable. Therefore, the type of property, the dimension of the buildings and the situation within the case study area is known.

As a first step to assess the damages to properties, an average of the maximum simulated water depth, of those surrounding a building, was associated to each property. After this a new methodology, based on conversations with a surveyor expert in damages due to floods, is proposed to determine the water depth inside the building. The main idea in this approach is that a "sealing coefficient" (Sc) could determine the difference between the water depth outside and inside the property. It is defined as the ratio between the water depth inside and outside the building, therefore it will range from 0 (no water depth inside) to 1 (same water depth inside and outside). Accordingly, relations between 
water depth outside and inside the buildings have been developed, specifically for the 14 types of properties considered (Figure $\mathrm{7b}$ ). It was assumed that generally the residence time of the flooding is not enough for the building to leak until the water levels outside and inside become equal. Cases in which water enters directly through open doors and windows will not be considered since these are supposed to be closed because people are expected to be properly warned. However, the higher the water depth outside is, the higher the sealing coefficient will be. In other words, when the water depth outside is high enough, the water depth inside the building is expected to be the same that the outside one. Therefore, the sealing coefficient is a function of the water depth outside and also of the type of property (Figure $7 \mathrm{~b}$ ).

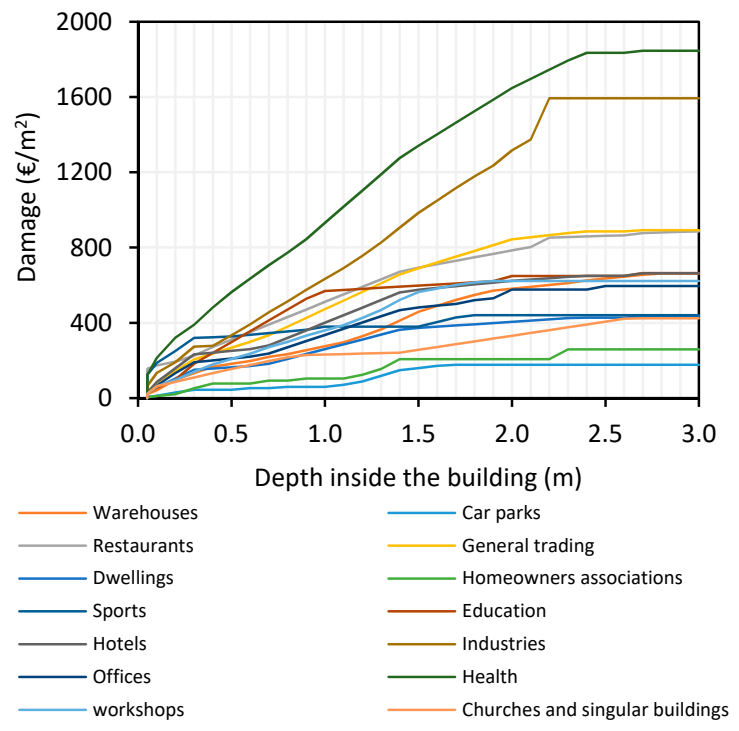

(a)

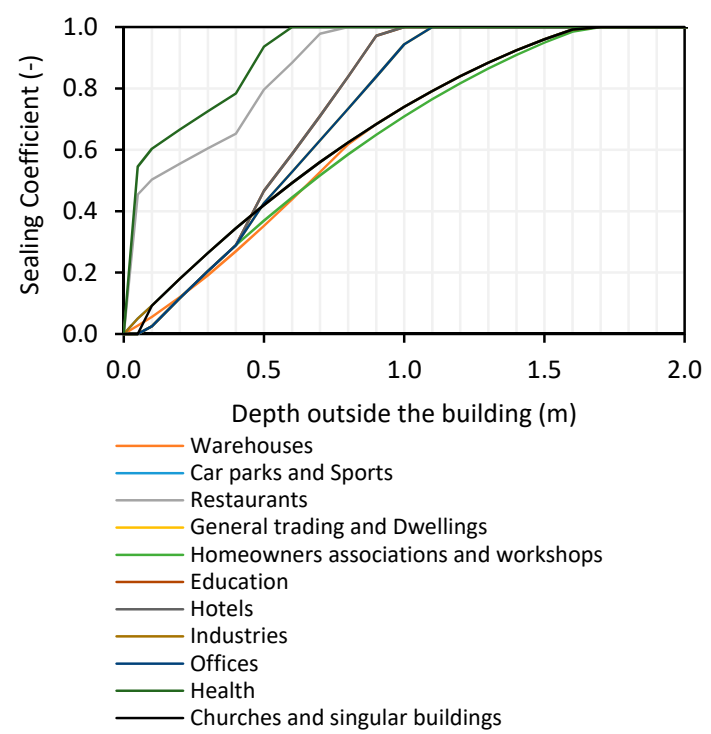

(b)

Figure 7. (a) Depth-damage and (b) sealing coefficients curves developed for Badalona case study.

In this model also a maximum of two levels of basements were considered, according to the information obtained from the Spanish cadastre. In case of the existence of basement, either one or two levels, two model parameters representing reference water depths were defined: The maximum depth and the residual depth. The former indicates that this water level is not expected to be exceed due to the steady water flow from the ground floor to the basement, and thus from the 1st basement level to the second. There may be several connections to let the water leak from one floor to the other but stairwells are supposed to be the main ones. Therefore, the maximum damage in a floor with an underneath level will be related to the maximum water depth. On the other hand, a residual water level has been defined, which determines the water volume which will be stored in this level and, hence, will not affect the underneath level.

The presence of front steps for each building across the studied urban area were taken into account also, by relating an average height of the front steps to each type of property. In this manner, the water depth in contact with the building façade will be reduced according to the front steps' height. Whereas the water depth in the ground floor will be lower than the outside one, basements act as small water storage tanks and water depths could even become higher than those present on the streets. This model was implemented in the GIS software in order to establish a water depth inside the buildings and compute the corresponding damage, based on the previously presented rules. Regarding the damage assessment for vehicles in Badalona, the methodology proposed by Martínez-Gomariz et al. [17] has been implemented for the different floods related to design storms for different return periods.

The proposed methodology developed to assess indirect damages in the context of urban floods is the input-output model, which allows to estimate the ratio of indirect damage over direct damages 
across the different economic sectors of the affected area. It follows the method developed within the European project PEARL (2014-2018) with the same purpose that Kowalewski [41], which is particularly relevant for the present case study, as it was specifically developed to evaluate indirect economic damage from flood events at a regional scale, although it has been downscaled to the county scale and adapted to the requirements of this case study.

Taking into account data availability and uncertainty, the input-output method offered the most effective solution to reach the indirect damage estimation objective. The data sources are the input-output table (IOT) for Catalonia (the latest published is for 2014) together with employment figures categorized by economic sector for Catalonia and Barcelonès County [42], and the historical data of claims paid by the Spanish insurance company (CCS). The IOT is a matrix that registers the use of factors of production by each economic sector in the production of final goods and services of a certain economy. From the Catalonian IOT, downscaling to county-level is based on simple rules relative to the size of employment in each sector in this county. Drawing on Leontief's production functions-cross-sectorial interdependencies of intermediate goods and final demand-the model interprets the data recorded in the table and assess the economic consequences of external shocks to the system (e.g., resulting from flood events). The final input-output account then captures the supply and demand interactions of the economic sectors downscaled to sub-regional level.

As a novelty, this version considers the IOT of Catalonia as baseline, downscaling to county level-Barcelonès-compared to the previous work, which uses national tables as baseline and downscale to the regional level. An exogenous shock is then introduced, obtained from the paid claims of CCS historical data. For Badalona 41 cases registered were included. This dataset is previously re-classified by economic sectors: from 4 types of land uses (industry, offices, retail, and vehicles) to 10 types of economic sectors used in the IOT. From the interdependencies of sectors, the model is able to simulate how damages spread across the economy, which is interpreted as indirect damages. This allows to estimate an average ratio of indirect to direct damages, in order to obtain the ratio to estimate this relationship for any direct damage quantity estimated for Badalona. Finally, the ratio is applied to the estimated direct damages per return period to obtain the total EAD under all proposed scenarios.

\section{Results}

This study has provided qualitative and quantitative results. The firsts are the maps allow to spot the critical areas for the city and also make possible a visual comparison of risks under current and future rainfall conditions (Figures 8 and 9).

The knowledge of the city from the Badalona city council technicians enabled the validation of the results, by identifying accordingly the hot spots of the city. The zoomed area in Figures 8 and 9 is one of the most affected by floods historically and the models responded appropriately. From Figures 8 and 9 the expected increase of damages (tangible and intangible) under a business as usual situation (i.e., do nothing under future rainfall conditions) in case of a flood caused by a 100-year return period rainfall can be visually identified.

On the other hand, the obtained quantitative results in terms of high risk areas are presented in Figure 10 together with the climate change factors associated to each return period considered. According to these outcomes an important percentage increment of high risk area for pedestrians for low return periods (39\% for T2 and $42 \%$ for T10) and for vehicles (17\% for T2 and $39 \%$ for T10). However, both for T2 and T10 the increment of high-risk area in terms of absolute values is not significant, particularly for vehicles. Whereas, higher return-period rainfalls (T100 and T500) would cause important increase of high risk areas and thus their expected percentage increment would be translated into relevant absolute-value increments of high risk area. Risk for pedestrians is predicted to increase up to $9 \%$ and 3\% for T100 and T500 respectively. Finally, risk for vehicles would increase up to $18 \%$ and $5 \%$ for 100 -year and 500 -year return period respectively. 


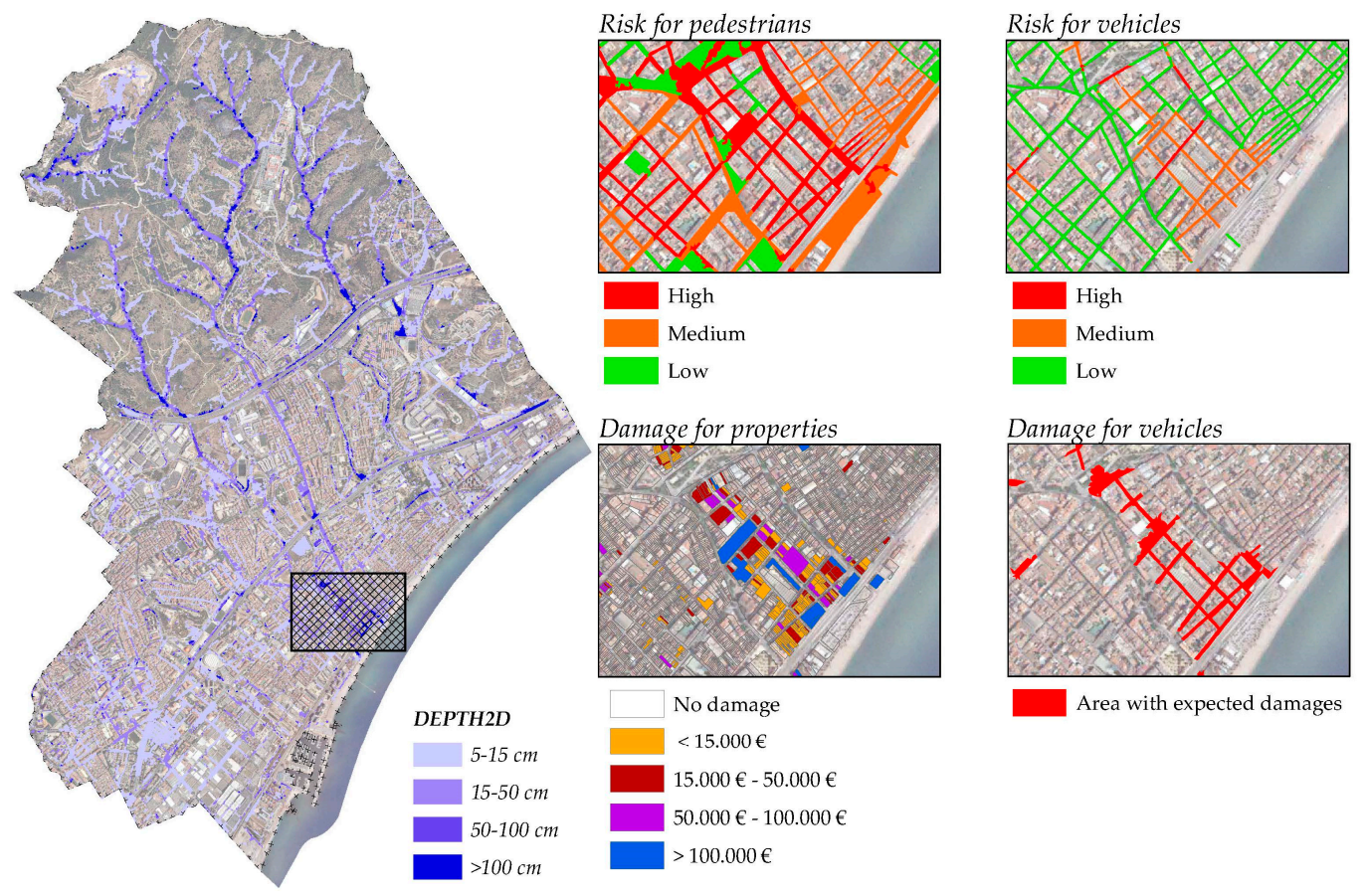

Figure 8. Flood related to a 100-year return period design storm under current rainfall conditions and the corresponding calculated damages within a zoomed area (black frame in the flood map).

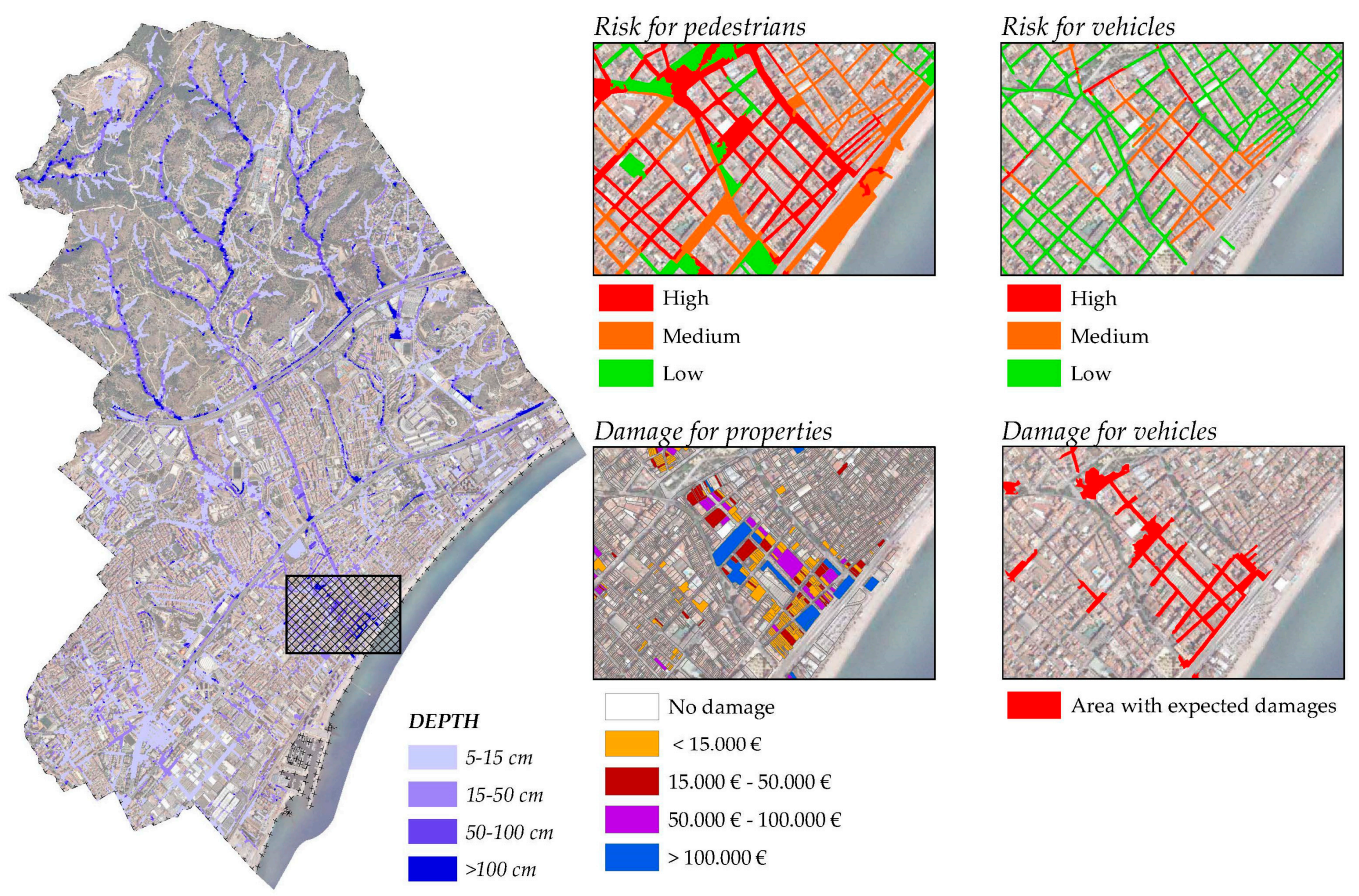

Figure 9. Flood related to a 100-year return period design storm under future rainfall conditions and the corresponding calculated damages within a zoomed area (black frame in the flood map). 


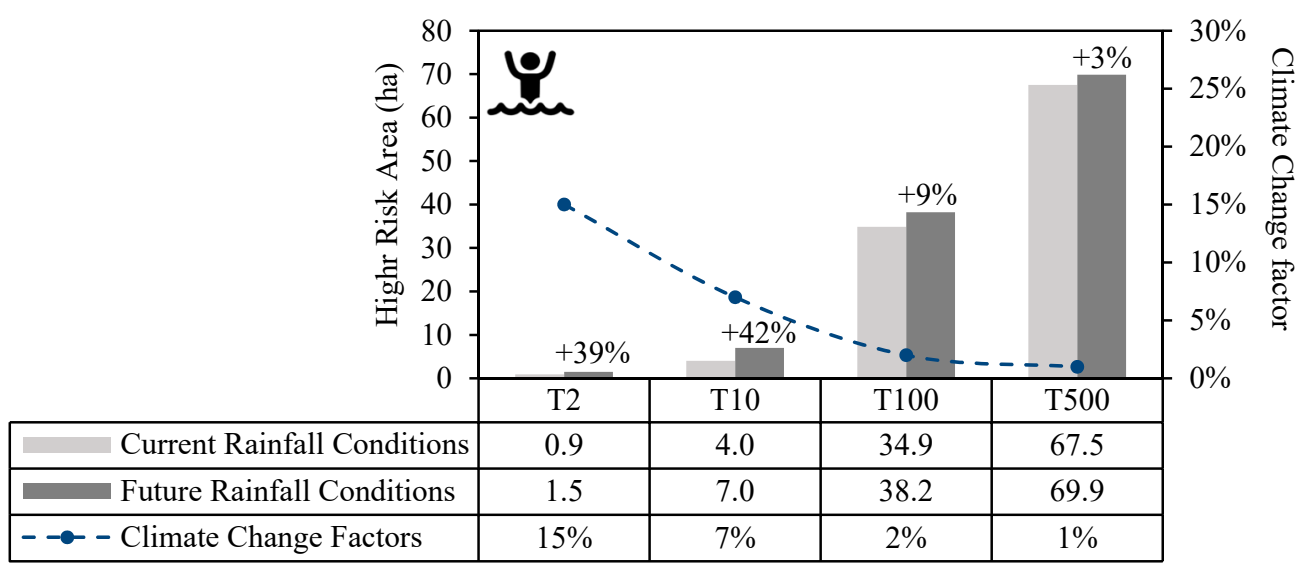

(a)

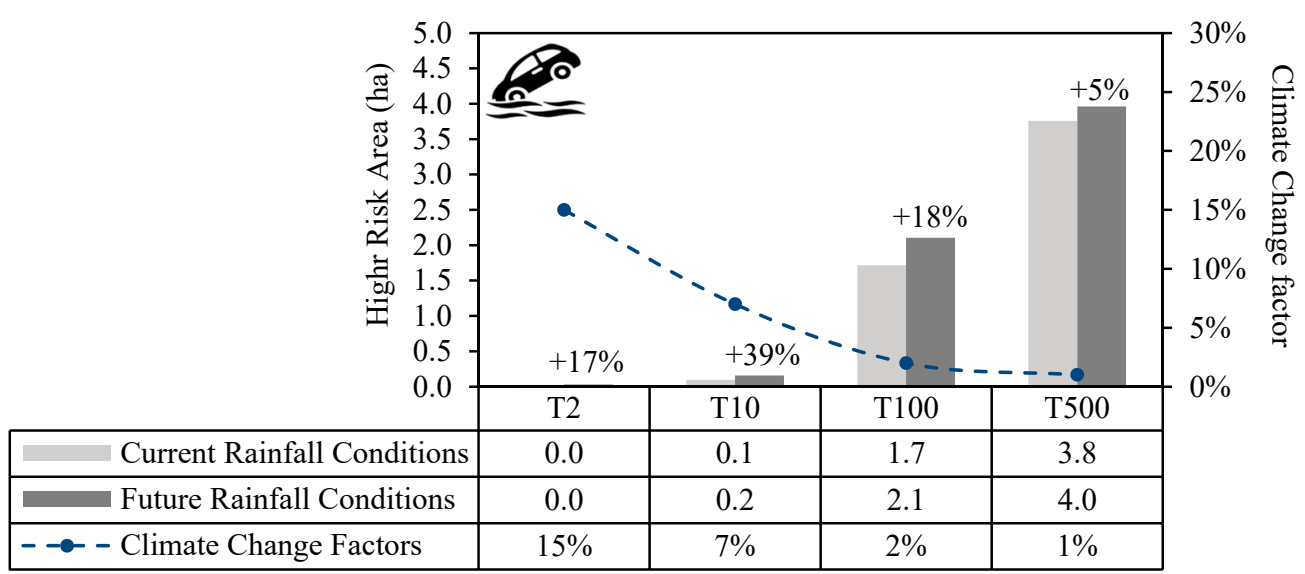

(b)

Figure 10. High risk areas for (a) pedestrians and (b) vehicles) according to current and future rainfall conditions.

The expected annual damage (EAD) is the indicator used here to measure changes in flood impacts according to expected future rainfall conditions (RCP 8.5). Once the direct and indirect damages are estimated according to the methodologies described, the EAD can be obtained. It may be calculated through the integration of the area under the curve that Figure 11 shows, result from plotting probability of occurrence of the damage and its monetary value [43].

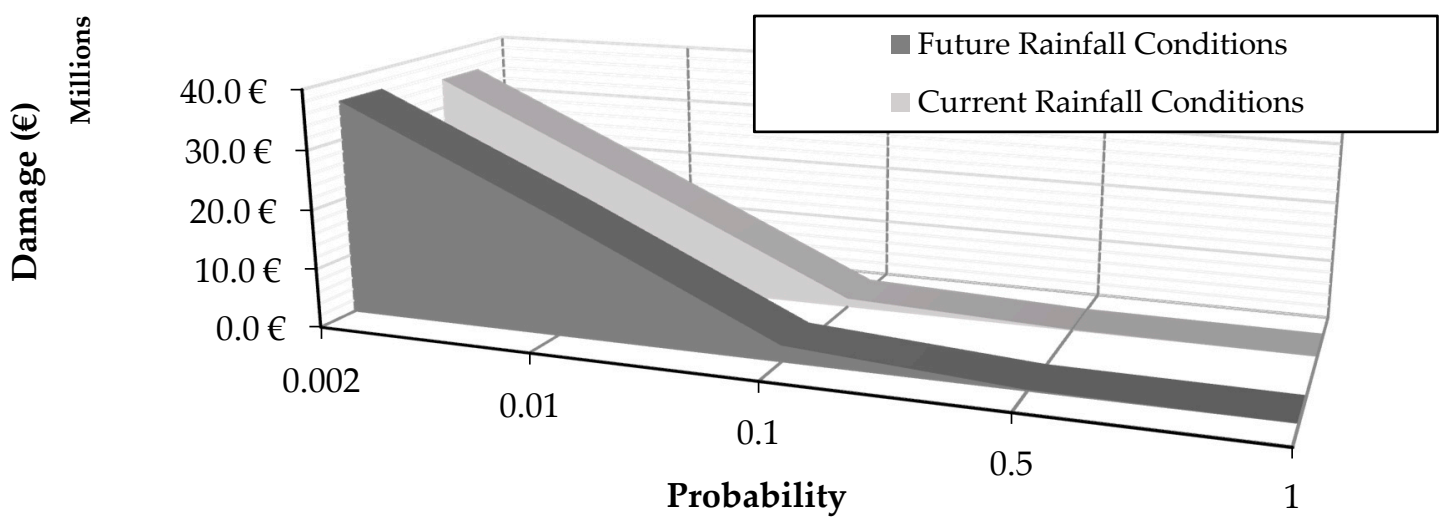

Figure 11. Damage-probability curve for current and future rainfall conditions. Both direct and indirect damages are considered. 
Regarding indirect damages, the application of the Input/Output Method yields an estimation of indirect damages percentage over the expected direct damages of $32 \%$. This ratio has been applied to each return period (i.e., T2, T10, T100, and T500) to calculate the EAD. The sectorial distribution of the direct impacts, used for the estimation of the indirect damages, yielded results in the form of a range of values. For the EAD estimation, the average value has been used. The results have been contrasted with relevant indirect damage studies, obtaining positive results. Carrera et al. [44] obtained results in the range of 0.19-0.22 for indirect damages in an Italian case study, while Hallegatte et al. [45] presented results in the range of $0.13-0.44$ for a case study in the USA. The validation with real data has been proved difficult since insurance figures only show the accepted claims for businesses that have contracted the premium cover for business closure due to a weather event, which is a very limited number.

The total EAD, considering both direct and indirect damages estimation, is presented in Table 4, which includes the breakdown of estimated damages for current and future rainfall conditions. According to these results it is found a predicted increase of $30 \%$ in terms of EAD.

Table 4. Direct and indirect damages estimated for the different return periods and both current and future rainfall conditions.

\begin{tabular}{|c|c|c|c|c|}
\hline \multicolumn{5}{|c|}{ Current Rainfall Conditions } \\
\hline Return Period (years) & 2 & 10 & 100 & 500 \\
\hline Probability & 0.5 & 0.1 & 0.01 & 0.002 \\
\hline Direct damage to properties $(€)$ & $80,011.49 €$ & $1,023,592.69 €$ & $13,129,075.21 €$ & $24,440,088.96 €$ \\
\hline Direct damage to vehicles $(€)$ & $31,237.45 €$ & $130,035.63 €$ & $1,146,728.53 €$ & $2,655,441.99 €$ \\
\hline Indirect damage due to businesses interruption $(€)$ & $33,374.68 €$ & $346,088.50 €$ & $4,282,741.12 €$ & $8,128,659.29 €$ \\
\hline Damage $(€)$ & $144,623.62 €$ & $1,499,716.81 €$ & $18,558,544.86 €$ & $35,224,190.24 €$ \\
\hline Expected Annual Damage (EAD) & \multicolumn{4}{|c|}{$1,482,776.71 €$} \\
\hline \multicolumn{5}{|c|}{ Future rainfall conditions (RCP 8.5) } \\
\hline Return Period (years) & 2 & 10 & 100 & 500 \\
\hline Probability & 0.5 & 0.1 & 0.01 & 0.002 \\
\hline Direct damage to properties $(€)$ & $139,454.19 €$ & $1,926,720.27 €$ & $14,289,199.05 €$ & $25,364,007.72 €$ \\
\hline Direct damage to vehicles $(€)$ & $62,300.55 €$ & $199,121.48 €$ & $1,228,946.61 €$ & $2,770,779.08 €$ \\
\hline Indirect damage due to businesses interruption $(€)$ & $60,526.42 €$ & $637,752.53 €$ & $4,655,443.70 €$ & $8,440,436.04 €$ \\
\hline Damage $(€)$ & $262,281.16 €$ & $2,763,594.28 €$ & $20,173,589.36 €$ & $36,575,222.84 €$ \\
\hline Expected annual damage (EAD) & \multicolumn{4}{|c|}{$1,929,913.89 €$} \\
\hline
\end{tabular}

\section{Conclusions}

As an important part of the research carried out in the BINGO project, a comprehensive flood risks and damages assessment was conducted, obtaining estimations of how projected future rainfall conditions may affect the economy and citizens' safety in the municipality of Badalona. In order to assess social and economic risks caused by floods in Badalona, firstly a detailed 1D/2D hydrodynamic model was developed and calibrated to provide estimations of the floods that could occur related to different return periods (i.e., 2, 10, 100, and 500 years). The risk definition here considers the combination of hazard and vulnerability, being the vulnerability concept formed by susceptibility and exposure. Risks considered in this study may be divided into intangible (social) and tangible (economic) damages, and also direct and indirect. Different methodologies have been proposed in this article in order to assess these risks in Badalona, with the aim of understanding how projected future rainfall would affect the city. The obtained outcomes can be useful to evaluate the efficiency of flood adaptation measures in Badalona, which can be prioritized based on risk reduction criteria with the results presented herein. Moreover, the city council, thanks to the obtained results, will be able to design new drainage elements according to future rainfall conditions to guarantee a certain level of safety conditions. Although, the city hot spots were well known by the city council technicians, the obtained results allowed them to better understand, quantify and analyze the cost of inaction. This study may be seen as an extension or enhancement of classical Master Drainage Plans, which scope 
traditionally ends by designing pipes and tanks for a specific security level (i.e., a design storm related to a return period). This conventional approach is far different from the concept of dual drainage which proposes to give response to what will happen on the streets once this security level is exceeded (i.e., rainfalls higher than the design storm). The criteria and methodologies presented in this article include details enough to be replicated in other cities.

Author Contributions: Hydrodynamic 1D/2D coupled model, B.R. and L.L.; Current and Future rainfall conditions scenarios, E.M.-G. and M.M.; full detailed flood risk assessment methodology, E.M.-G., M.G., M.M. and B.R.; flood risk assessment implementation and analysis of results; E.M.-G. and L.L.; writing-original draft preparation, E.M.-G.; writing—review and editing, L.L., M.G.; visualization, M.M.; supervision, B.R.; project administration, M.M.; funding acquisition, M.M.

Funding: This research was funded by EU H2020, Grant Agreement No. 641739.

Acknowledgments: The authors thank the Spanish insurance company Consorcio de Compensación de Seguros (CCS) for its important role in this research. Without its collaboration by providing claims data the damage model would have not been calibrated properly.

Conflicts of Interest: The authors declare no conflict of interest.

\section{References}

1. Intergovernmental Panel on Climate Change (IPCC). Climate Change 2014: Synthesis Report; IPCC: Geneva, Switzerland, 2014.

2. The European Parliament and the Council of the European Union. Directive 2007/60/Ec of the European Parliament and of the Council of 23 October 2007 on the Assessment and Management of Flood Risks (Text with EEA Relevance); The European Parliament and the Council of the European Union: Brussels, Belgium, 2007.

3. Zhou, Q.; Mikkelsen, P.S.; Halsnæs, K.; Arnbjerg-Nielsen, K. Framework for economic pluvial flood risk assessment considering climate change effects and adaptation benefits. J. Hydrol. 2012, 414-415, 539-549. [CrossRef]

4. Turner, B.L.; Kasperson, R.E.; Matson, P.A.; McCarthy, J.J.; Corell, R.W.; Christensen, L.; Eckley, N.; Kasperson, J.X.; Luers, A.; Martello, M.L.; et al. A framework for vulnerability analysis in sustainability science. Proc. Natl. Acad. Sci. USA 2003, 100, 8074-8079. [CrossRef] [PubMed]

5. Velasco, M.; Russo, B.; Cabello, À.; Termes, M.; Sunyer, D.; Malgrat, P. Assessment of the effectiveness of structural and nonstructural measures to cope with global change impacts in Barcelona. J. Flood Risk Manag. 2018, 11, S55-S68. [CrossRef]

6. Hofmann, J.; Schüttrumpf, H.; Hofmann, J.; Schüttrumpf, H. Risk-Based Early Warning System for Pluvial Flash Floods: Approaches and Foundations. Geosciences 2019, 9, 127. [CrossRef]

7. Freni, G.; La Loggia, G.; Notaro, V. Uncertainty in urban flood damage assessment due to urban drainage modelling and depth-damage curve estimation. Water Sci. Technol. 2010, 61, 2979-2993. [CrossRef] [PubMed]

8. Martínez-Gomariz, E.; Guerrero-Hidalga, M.; Russo, B.; Yubero, D.; Gómez, M.; Castán, S. Desarrollo y validación de curvas de daño y estanqueidad para la estimación de daños por inundaciones en zonas urbanas españolas. In Proceedings of the VI Jornadas de Ingeniería del Agua JIA2019, Toledo, Spain, 1 October 2019; p. 4.

9. Department of Natural Resources and Mines (Queensland Government). Guidance on the Assessment of Tangible Flood Damages; Department of Natural Resources and Mines: Brisbane, Australia, 2002.

10. Federal Emergency Management Agency (FEMA); Department of Homeland Security. Mitigation Division Multi-hazard Loss Estimation Methodology. Flood Model. Hazus-HM MR5 Technical Manual; FEMA: Washington, DC, USA, 2015; p. 499.

11. Francés, F.; García-Bartual, R.; Ortiz, E.; Salazar, S.; Miralles, J.L.; Blöschl, G.; Komma, J.; Habereder, C.; Bronstert, A.; Blume, T. Efficiency of Non-Structural Flood Mitigation Measures: "Room for the River" and "Retaining Water in the Landscape"; EU: Brussels, Belgium, 2008.

12. Luino, F.; Cirio, C.G.; Biddoccu, M.; Agangi, A.; Giulietto, W.; Godone, F.; Nigrelli, G. Application of a model to the evaluation of flood damage. Geoinformatica 2009, 13, 339-353. [CrossRef]

13. Penning-Rowsell, E.; Viavattene, C.; Pardoe, J.; Chatterdon, J.; Parker, D.; Morris, J. The Benefits of Flood and Coastal Risk Management: A Handbook of Assessment Techniques; Middlesex University Press: London, UK, 2010; p. 90. 
14. Velasco, M.; Cabello, À.; Russo, B. Flood damage assessment in urban areas. Application to the Raval district of Barcelona using synthetic depth damage curves. Urban Water J. 2015, 13, 426-440. [CrossRef]

15. Messner, F.; Meyer, V. Flood Damage, Vulnerability and Risk Perception-Challenges for Flood Damage Research; UFZ-Diskussionspapiere, No. 13/2005; Springer: Berlin, Germany, 2006.

16. Grigg, N.S.; Helweg, O.J. State-of-the-Art of Estimating Flood Damage in Urban Areas. J. Am. Water Resour. Assoc. 1975, 11, 379-390. [CrossRef]

17. Martínez-Gomariz, E.; Gómez, M.; Russo, B.; Sánchez, P.; Montes, J.-A. Methodology for the damage assessment of vehicles exposed to flooding in urban areas. J. Flood Risk Manag. 2019, 12, e12475. [CrossRef]

18. Thieken, A.; Ackermann, V.; Elmer, F.; Kreibich1, H.; Kuhlmann, B.; Kunert, U.; Maiwald, H.; Merz, B.; Müller, M.; Piroth, K.; et al. Methods for the evaluation of direct and indirect flood losses. In Proceedings of the 4th International Symposium on Flood Defence: Managing Flood Risk, Reliability and Vulnerability, Toronto, ON, Canada, 6-8 May 2008; p. 10.

19. Hammond, M.J.; Chen, A.S.; Djordjević, S.; Butler, D.; Mark, O. Urban flood impact assessment: A state-of-the-art review. Urban Water J. 2015, 12, 14-29. [CrossRef]

20. Ranger, N.; Hallegatte, S.; Bhattacharya, S.; Bachu, M.; Priya, S.; Dhore, K.; Rafique, F.; Mathur, P.; Naville, N.; Henriet, F.; et al. An assessment of the potential impact of climate change on flood risk in Mumbai. Clim. Chang. 2011, 104, 139-167. [CrossRef]

21. Gómez, M.; Russo, B. Methodology to estimate hydraulic efficiency of drain inlets. Proc. ICE Water Manag. 2011, 164, 81-90. [CrossRef]

22. Russo, B.; Sunyer, D.; Velasco, M.; Djordjević, S. Analysis of extreme flooding events through a calibrated 1D/2D coupled model: The case of Barcelona (Spain). J. Hydroinform. 2015, 17, 473-491. [CrossRef]

23. Gómez, M.; Rabasseda, G.H.; Russo, B. Experimental campaign to determine grated inlet clogging factors in an urban catchment of Barcelona. Urban Water J. 2013, 10, 50-61. [CrossRef]

24. Gómez, M.; Parés, J.; Russo, B.; Martínez-Gomariz, E. Methodology to quantify clogging coefficients for grated inlets. Application to SANT MARTI catchment (Barcelona). J. Flood Risk Manag. 2019, 12, e12479. [CrossRef]

25. Henonin, J.; Russo, B.; Mark, O.; Gourbesville, P. Real-time urban flood forecasting and modelling-a state of the art. J. Hydroinform. 2013, 15, 717-736. [CrossRef]

26. BINGO Project. Deliverable D3.3: Calibrated Water Resources Models for Past Conditions, H2020 BINGO. Bringing Innov. to on GOing Water Management-a Better Future; under Clim. Chang. Grant Agreem. n 641739; EU: Brussels, Belgium, 2019.

27. Houston, D.; Werrity, A.; Bassett, D.; Geddes, A. Pluvial (Rain-Related) Flooding in Urban Areas: The Invisible Hazard; Joseph Rowntree Foundation: York, UK, 2011.

28. Larsen, A.N.; Gregersen, I.B.; Christensen, O.B.; Linde, J.J.; Mikkelsen, P.S. Potential future increase in extreme one-hour precipitation events over Europe due to climate change. Water Sci. Technol. 2009, 60, 2205-2216. [CrossRef]

29. Arnbjerg-Nielsen, K. Quantification of climate change effects on extreme precipitation used for high resolution hydrologic design. Urban Water J. 2012, 9, 57-65. [CrossRef]

30. Smith, K.; Ward, R. Floods: Physical Processes and Human Impacts; John Wiley \& Sons: Chichester, UK, 1998; ISBN 0-471-95248-6.

31. Merz, B.; Kreibich, H.; Thieken, A.; Schmidtke, R. Estimation uncertainty of direct monetary flood damage to buildings. Nat. Hazards Earth Syst. Sci. 2004, 4, 153-163. [CrossRef]

32. Djordjevic, S.; Prodnovic, D.; Maksimovic, C. An approach to simulation of dual drainage. Water Sci. Technol. 1999, 39, 95-103. [CrossRef]

33. Russo, B. Design of Surface Drainage Systems According to Hazard Criteria Related to Flooding of Urban Areas. Ph.D. Thesis, Technical University of Catalonia, Barcelona, Spain, 2009.

34. Russo, B.; Gómez, M.; Macchione, F. Pedestrian hazard criteria for flooded urban areas. Nat. Hazards 2013, 69, 251-265. [CrossRef]

35. Martínez-Gomariz, E. Inundaciones Urbanas: Criterios de Peligrosidad y Evaluación del Riesgo Para Peatones y Vehículos, 1st ed.; Universitat Politècnica de Catalunya: Barcelona, Spain, 2016; ISBN 978-84-617-4904-1.

36. Martínez-Gomariz, E.; Gómez, M.; Russo, B. Experimental study of the stability of pedestrians exposed to urban pluvial flooding. Nat. Hazards 2016, 82, 1259-1278. [CrossRef] 
37. Martínez-Gomariz, E.; Gómez, M.; Russo, B.; Djordjević, S. A new experiments-based methodology to define the stability threshold for any vehicle exposed to flooding. Urban Water J. 2017, 14, 930-939. [CrossRef]

38. Martínez-Gomariz, E.; Gómez, M.; Russo, B.; Djordjević, S. Stability criteria for flooded vehicles: A state-of-the-art review. J. Flood Risk Manag. 2018, 11, S817-S826. [CrossRef]

39. Gerard, M. Tire-Road Friction Estimation Using Slip-Based Observers; Lund University: Lund, Sweden, 2006.

40. Martínez-Gomariz, E.; Guerrero-Hidalga, M.; Russo, B.; Yubero, D.; Gómez, M.; Castán, S. Desarrollo y aplicación de curvas de daño y estanqueidad para la estimación del impacto económico de las inundaciones en zonas urbanas españolas. Ing. Del Agua 2019, 23, 229-245. [CrossRef]

41. Kowalewski, J. Methodology of the Input-Output Analysis. Available online: https://www.econstor.eu/ handle/10419/48249 (accessed on 6 February 2019).

42. IDESCAT, S.I. of C. Population Growth. Available online: http://www.idescat.cat/emex/?id=080193\&lang=en (accessed on 6 February 2019).

43. Meyer, V.; Priest, S.; Kuhlicke, C. Economic evaluation of structural and non-structural flood risk management measures: Examples from the Mulde River. Nat. Hazards 2011, 62, 301-324. [CrossRef]

44. Carrera, L.; Standardi, G.; Bosello, F.; Mysiak, J. Assessing direct and indirect economic impacts of a flood event through the integration of spatial and computable general equilibrium modelling. Environ. Model. Softw. 2015, 63, 109-122. [CrossRef]

45. Hallegatte, S. An Adaptive Regional Input-Output Model and its Application to the Assessment of the Economic Cost of Katrina. Risk Anal. 2008, 28, 779-799. [CrossRef]

(C) 2019 by the authors. Licensee MDPI, Basel, Switzerland. This article is an open access article distributed under the terms and conditions of the Creative Commons Attribution (CC BY) license (http://creativecommons.org/licenses/by/4.0/). 